\title{
MANIFESTATIONS OF MILITARY CONFLICTS IN THE CURRENT OPERATIONAL ENVIRONMENT
}

\author{
Aurelian RAȚIU*, Cătălin CIOACĂ** \\ *6"Nicolae Bălcescu" Land Forces Academy, Sibiu, Romania \\ **"Henri Coandă" Air Forces Academy, Brașov, Romania \\ ratiu.aurelian@armyacademy.ro, catalin_cioaca@yahoo.com
}

\begin{abstract}
The study of the military phenomenon can only be achieved by analyzing it in connection with other processes of social life and within the complex conditions determined by a set of political, social, economic, international, technological, etc factors. Thus, this research aims at identifying and presenting the main features of the military conflicts predictable in the future. Also, we made an analysis of the fundamental elements of the operational environment, from the perspective of the identified types of conflicts.
\end{abstract}

Keywords: military conflicts, conventional military conflict, irregular warfare, operational environment

\section{Introduction}

Major wars or military confrontations have always impacted the great revolutions of mankind, putting their mark on the evolution and development of man, contributing to the formation of a certain type of society.

Nowadays, the contemporary military phenomenon includes, besides conventional military actions, political-diplomatic, economic, and informational (imago logical, psychological, cybernetic) actions. Even in these conditions, a certain place is taken by combat, presented as an assembly of violent military actions, performed in an organized manner between two armed forces groups aiming at accomplishing opposing goals.

The contemporary military phenomenon is still manifested in many cases by combat, in which conventional forces and means carry out kinetic actions that cause significant destruction and considerable material and human losses. The military action (combat) is carried out by military forces under certain particular conditions of time and space, but it is dependent on a number of factors: political, economic, psycho-moral, military etc. These factors interact with each other and determine both the physiognomy of actions, and their development and outcome.

According to current trends, the military conflict of the future will be par excellence atypical and it is assumed that: the place of the armored groups will be taken over by the information and psychological actions, the infantry divisions will be replaced by low-value structures with great mobility and flexibility, and large-scale operations will be replaced by precision operations against vital targets.

\section{Manifestations of military conflicts}

As far as the current military conflicts are concerned, one can notice a change in the manifestation of the forces in the confrontation space. The beginning of the 
21 st century highlighted a new trend in the conduct of military operations, giving them a deep joint character (joint operations) by involving all categories of forces within the same military operation. But today, the traditional spaces of conflict (land, air and maritime) will be complemented by the informational and the space environment. The super saturation of the terrestrial space with means of impact, as well as the diminishing of the possibility of surprise when using ground-based weapon systems, required the development of means disposed in the extra-atmospheric space, which led to the evolution and diversification of airborne systems, characterized mainly by high speed of action and strong destruction power.

According to the conducted content analysis, most analysts and theorists in the field agree that, at the beginning of the century, two types of military conflict are predictable:

1. Conventional military conflicts, armyagainst-army type, which can be of small, medium or high intensity, conducted between states included in the category of local or regional competitors.

2. Irregular Warfare, army-against-army and/or armies-and-other paramilitary structures type, conducted between global and/or regional competitors and niche competitors.

\subsection{The Conventional Military Conflict}

Current developments in the security/operational environment offer the premises of the analysis on the basis of which it is concluded that, at present, two representative types of conventional military conflicts are possible:

a) major combat (large-scale conflict) at the level of an extended theater of military operations;

b) local/limited conflict, which could take place both as an interstate and intrastate conflict.

Each of the two types of conflict is differentiated, individualized by specific elements: the intensity of violence, the magnitude of the actions, the amount of used forces, the types of military means.

a) The major combat can arise between states or alliances/state coalitions. Most likely, such a type of conflict may arise between weakly governed or ungoverned ("failed") states or between such states and other more developed states.

The military actions specific to this type of confrontation will be planned and carried out in order to achieve decisive results in a short time, rapidly achieving the objectives of particular importance, and minimizing the losses within the fighting forces.

At the same time, such military actions will be carried out through large concentrations of conventional forces, allowing the exploitation of technological superiority and the manifestation of the offensive character.

The groups of forces will be well-equipped, diversified and specialized, with increased power of destruction and capacity of action. The development of intelligent weapons and ammunition makes it possible to conduct military actions across the entire area of responsibility, to quickly exploit the initial results, to execute "surgical" blows and to act upon the most important centers of gravity. Forces will strike at vital points, benefiting from a considerable amount of information that will lead to more types of action, as well as to the ability to use forces and means without restrictions regarding time, season, land.

The battlefield will experience a continuous evolution through which past features will be invalidated and new ones will be gained, such as multidimensionality, decisiveness, speed, fluidity, flexibility, dynamism, convergence, discontinuity, omni directionality, automation and digitization [1].

b) The local/limited conflict (it should not be understood ad litteram - Low Intensity Conflict -, the American concept) includes a range of military operations and actions having a joint, integrated character, but with limited objectives. Also, the magnitude of 
the battles, the types of actions, the value of the forces and the quantities of the engaged means are relatively low.

The organizational structures are more flexible, maneuverable, and carry battles focused on "hotbeds" (limited targets), and keeping the land is no longer an end in itself; it remains the natural frame of destroying the opponent. In the main actions, the sudden and rapid changes in situations due to the realization and exploitation of surprise can lead to the frequent alternation of battle forms and procedures.

\subsection{The Irregular Warfare}

Starting the description with the classification criterion depending on the combat methods used, we can say that this type of conflict characterizes a wide variety of military confrontations that do not correspond to the classic features. The unconventional conflict has had, in time, many names: war of harassment, insurrection, subversive action, guerrilla, asymmetric war, terrorism, etc. Therefore, currently, the concept of irregular warfare (IW), covering all this variety of conflicts/wars/aggressions, is used.

Thus, the irregular conflict is the confrontation in which one or more parties involved adopt asymmetric/non-traditional methods aimed at supporting or undermining the credibility and/or the legitimacy of government/ power authorities in a state or region.

The atypical/irregular features of these conflicts could be [2]:

- Each party seeks to avoid the battlefield in which the other is strong and prefers to strike with the means at its disposal or which it can obtain at low cost;

- Unconventional methods and unconventional means (for example, the terrorism attempts to completely avoid military/security forces and to directly hit civilian unprotected targets), appropriate and surprising attacks will mainly be used;

- The elements of terrorist organizations and insurgent groups intertwine, uniting their resources, forces and efforts to achieve common goals;

- It is intended to achieve significant psychological effects, especially on the civilian population, in the sense of undermining the credibility and/or legitimacy of government authorities;

- Continuously improving the means of realizing propaganda, diversifying the methods of manipulating population and creating a state of uncertainty.

Eventually, the irregular conflict is a "political struggle with violent and nonviolent components. The struggle is for control or influence over, and the support of, a relevant (neutral civilian) population" [3]. The conflicting parties, whether state or armed groups, will try to undermine the legitimacy and credibility of their opponents. At the same time, through political, military, psychological and economic methods, they seek to maintain their legitimacy and credibility so that they can exercise authority over the majority of the population.

Thus, in the irregular conflict, the neutral civilian population is the center of gravity for both sides involved in the conflict.

3. Fundamental elements of the operational environment in terms of predictable types of conflicts

The operational environment, as an element of the security environment, is defined as a complex "composite of the conditions, circumstances and influences that affect the employment of capabilities" [4] and which must be taken into account by leaders/commanders both in decisionmaking and in execution.

The operational environment will be characterized by a wide range of elements: the physical space of operations, information, technology, the cultural environment, the risk factors, threats, etc. The features and details for each of these elements will be different in each military campaign/ deployed mission. 
Some elements are independent of the political-military will, especially those found in an area of operations: physical environment, adversary, independent or unknown groups, population and its culture etc., but there are also others, equally important, such as the information capabilities of the deployed force or stakeholders with interests in the region.

In general, the most important constituent elements of the operational environment in which the Land Force structures will have to act are the following[5]: physical environment, threats and dangers, civil/local population, agencies and organizations, independent actors, unknown actors.

a) Terrain/Physical environment. The physical environment is the terrain where the military force will act; it is the geographical space with all its natural and man-made elements, which, one way or another, influence the organization, preparation and conduct of military actions. Military forces must be able to operate in a variety of areas, both in the classical ones: planes, hills and plateaus or mountainforested terrain, as well as in other regions, such as the Arctic, coastal (seaside) areas, jungle, desert or urban areas. Military campaigns often involve a combination of such environments/spaces.

The elements in the physical space (both natural and man-made) are of great importance for the conduct of military actions. Towns, high relief forms, large rivers, forests, etc., lead to partitioning the land, and the resulted sections usually include the districts, the courses of operations, the alignments to defend or conquer, and the tactical, operational or strategic objectives. Thus, all the military, but especially the leaders, must be physically and mentally prepared for unique challenges and for various difficulties that will arise according to the characteristics of the environment/terrain.

Climate and weather are also other elements of the physical environment that influence military action through temperature variations, rainfall patterns and air currents. Variations in atmospheric pressure, the time of light and darkness, wind regime also influence the process of equipping and feeding forces, the exploitation of combat equipment and the operation of weapons.

b) Threats and dangers. Threats may occur in various forms and come from groups such as:

- Conventional military forces, easily to identify due to the uniform and ,in sight" weapons, acting through armed struggle;

- Unconventional forces/insurgent or terrorist elements, hard to identify, acting through a combination of violence and subversion.

Also, the threat may initially take some form, but it can change over time. For example:

- Unconventional forces can support conventional forces, or;

- Conventional military forces, during a conflict, could turn into an insurgent group. In some cases, adverse forces can use hybrid threats. In these situations, a group can combine in a complementary way conventional and unconventional forces. In other cases, a single force can in itself adopt a combination of conventional and unconventional features. Some potential opponents can use advanced weapon systems in irregular/guerrilla tactics or can change irregular and conventional tactics, as appropriate.

Military forces must be prepared to use both lethal and non-lethal forces to counterattack the variety of threats and dangers. Tactics, techniques, procedures, insurance and protection measures, engagement rules, etc., must be tailored to these types of challenges specific to the current operational environment.

c) Civilian/local population. Most military operations take place among or affect the civilian population, and the military and military structures will have permanent contact with the local population. This requires leaders/commanders at all levels to 
consider, from the planning stage, the effects that military operations will have on "civilians, local communities and infrastructure" [6]. The approaches can vary:

- in the actions developed in an armed conflict the goal is to avoid civilian casualties by evacuating and/or resettling them, setting up refugee camps, etc

- in irregular or counter-insurgent conflicts, operations focus on protecting the civilian population against attacks and abuses from insurgent groups, as well as on support actions (rebuilding infrastructure elements, provision of medical and educational services, etc.) so that governmental and international coalition forces gain authority and legitimacy.

The desired and undesirable effects of military operations on the civilian population will, at the same time, be a key factor and a constraint in military planning. Thus, both the understanding of the local culture and the assessment of effects on operations and their outcomes will be vital.

d) Agencies and organizations. In the current and future operational environment, the military forces will be involved in supporting the actions of other governmental and non-governmental agencies and organizations, and they also support the efforts of military structures to reach the final goal of the campaign. These agencies and organizations can be „operationally" subordinated to military commanders to ensure the "integration of all actions and effects to achieve common goals" [7]. Coordinated involvement of several agencies working together with military forces will reflect a comprehensive approach to campaigns.

e) Unknown actors. Some actors in the operational environment will be considered unfamiliar from the point of view of support to security forces (if they give it or not). Indigenous actors will support the campaign if they believe that the final goals and purposes, as well as the methods/means to achieve them are legitimate or support their own interests. Their perception on legitimacy will depend on their culture and social expectations. Thus, military leaders will need to understand the perceptions and interests of these actors in order to act in their support and to protect them for the benefit of the campaign.

f) Independent actors. Some groups/organizations in the operational environment will act completely independently of military/government forces, even if their final objectives align with those of the campaign. Such groups will avoid interacting with military forces, following their own goals. Leaders/commanders must be aware of such organizations in their areas of responsibility and how they can affect the assigned missions.

\section{Conclusions}

In conclusion, future military conflicts require adaptable forces that move quickly from armed, lethal, and high-intensity combat operations to stabilization and reconstruction operations, or from peacekeeping operations to combat operations, in other words, forces that take action in the whole spectrum of military conflicts. Thus, the military actions in theaters of operations will often take place simultaneously at several levels of intensity along the entire spectrum of conflicts.

Military forces are called upon to carry out much faster and more precise operations, with a much greater rate of success, and, at the same time, restricted from the point of view of politics, of the area of action, and because of the public opinion sensitivity to human loss.

To meet these requirements, military forces must be:

- agile, expeditious, joint, integrated and fully interoperable;

- able to operate across the whole spectrum of conflicts;

- able to understand the cultural specificity of local communities and to protect/ support the civilian population in the area of operations; 
- able to interact efficiently with government civil authorities, organizations and other agencies in the theater of operations;

- technologically superior and capable of conducting network operations;

- given continuous and sufficient logistic support, regardless of the duration and pace of the operations.

As a consequence, a challenge of the future is represented by integrated/interdepartmental operations. This challenge is given by the harmonization of interests, action efforts and priorities of all participating structures/organizations, because many of them have cultural differences and pursue their own objectives or maintain their own independence. A significant contribution to achieving unity of effort lies in the profound understanding of the cultural, political, military and economic characteristics of the region in which the mission is carried out.

In this context, and in the absence of formal leadership relationships, the future integrated/interdepartmental forces must be proactive and improve their communication, planning, interoperability and ties with potential mission participants.

\section{References}

[1] Ionuţ Alin Cîrdei, The hybrid warfare in the $21^{\text {st }}$ century: an old concept with a new face, Proceedings 1 of $23^{\text {th }}$ International Scientific Conference „The Knowledge Based Organization", p.77, Sibiu, "Nicolae Bălcescu" Land Forces Academy Publishing House, 2017.

[2] Aurelian Raţiu, Gestionarea dinamicii conflictelor asimetrice, Sibiu, "Nicolae Bălcescu" Land Forces Academy Publishing House, 2012, pp. 46-47.

[3] Department of Defense, Irregular Warfare. Joint Operating Concept, 2007, p. 8, https://fas.org/irp/doddir/dod/iw-joc.pdf, accessed at 03.03.2019.

[4] AAP-06 - NATO Glossary of Terms and Definitions, NATO Standardization Office, 2018, p. 91.

[5] Chiefs of Staff, AJP-3.2.- Allied Joint Doctrine For Land Operations, NATO Standardization Office, 2016, p. I-3.

[6] Lucian Ispas, Paul Tudorache, Cultural Interoperability - Prerequisite for the Response to Hybrid Threats, Proceedings 1 of $23^{\text {th }}$ International Scientific Conference „The Knowledge Based Organization", p. 162, Sibiu, "Nicolae Bălcescu" Land Forces Academy Publishing House, 2017.

[7] Marius Pricopi, Military Integration - A Fundamental Condition for European Security and Stability, Land Forces Academy Review, Vol. 17, No. 2, p. 125-126, 2012. 